\title{
Suction-controlled experiments on Boom clay
}

\author{
F. Bernier ${ }^{\mathrm{a}, *}$, G. Volckaert ${ }^{\mathrm{a}}$, E. Alonso ${ }^{\mathrm{b}}, \mathrm{M}$. Villar ${ }^{\mathrm{c}}$ \\ a SCK.CEN, Nuclear Energy Research Establishment, Waste \& Disposal, Boeretang 200, B-2400 Mol, Belgium \\ ${ }^{\mathrm{b}}$ CIEMAT, Técnicas Geológicas, Avd. Complutense 22, 28040 Madrid. Spain \\ ${ }^{`}$ E.T.S. de Ingenieros de Caminos, Terhnical University of Catalunya, 080034 Barcelona, Spain
}

Received 18 December 1995; accepted 10 December 1996

\begin{abstract}
The understanding of the thermo-hydro-mechanical behaviour of a clay barrier is needed for the prediction of its final in situ properties after the hydration and thermal transient in a radioactive waste repository.

As part of the CEC 1990-1994 R\&D programme on radioactive waste management and storage, the CEA (Fr), CIEMAT (Sp), ENRESA (Sp), SCK · CEN (B), UPC (Sp) and UWCC (UJ) have carried out a joint project on unsaturated clay behaviour (Volckaert et al., 1996). The aim of the study is to analyse and model the behaviour of a clay-based engineered barrier during its hydration phase under real repository conditions. The hydro-mechanical and thermo-hydraulic models developed in this project have been coupled to describe stress/strain behaviour, moisture migration and heat transfer. A thermo-hydraulic model has also been coupled to a geochemical code to describe the migration and formation of chemical species.

In this project, suction-controlled experiments have been performed on Boom clay (B), FoCa clay ( $\mathrm{Fr}$ ) and Almeria bentonite ( $\mathrm{Sp}$ ). The aim of these experiments is to test the validity of the interpretive model developed by Alonso and Gens (Alonso et al., 1990), and to build a database of unsaturated clay thermo-hydro-mechanical parameters. Such a database can then be used for validation exercises in which in situ experiments are simulated.

The Boom clay is a moderately swelling clay of Rupellian age. It is studied at the SCK · CEN in Belgium as a potential host rock for a radioactive waste repository. In this paper, suction-controlled experiments carried out on Boom clay by SCK · CEN are described. SCK · CEN has performed experiments to measure the relation between suction, water content and temperature and the relation between suction, stress and deformation. The applied suctioncontrol techniques and experimental setups are detailed. The results of these experiments are discussed in the perspective of the model of Alonso and Gens. The influence of temperature on water uptake was rather small. The measured swelling-collapse behaviour can be explained by the Alonso and Gens model.
\end{abstract}

Keywords: Backfill material; Clay; Radioactive waste; Suction; Unsaturated behaviour

\section{Introduction}

Compacted expansive clays are proposed as engineered barriers in reference concepts for the

\footnotetext{
* Corresponding author. Tel.: + 3214333233 ; FAX: + 3214 323553.
}

disposal of heal-emitting nuclear waste in granite and clay. It is therefore important to understand the thermo-hydro-mechanical behaviour of these clay barriers to predict their final properties in the in situ conditions of a radioactive waste repository.

With this aim in view, the CEA, CIEMAT, ENRESA, SCK $\cdot$ CEN, UPC and UWCC have 


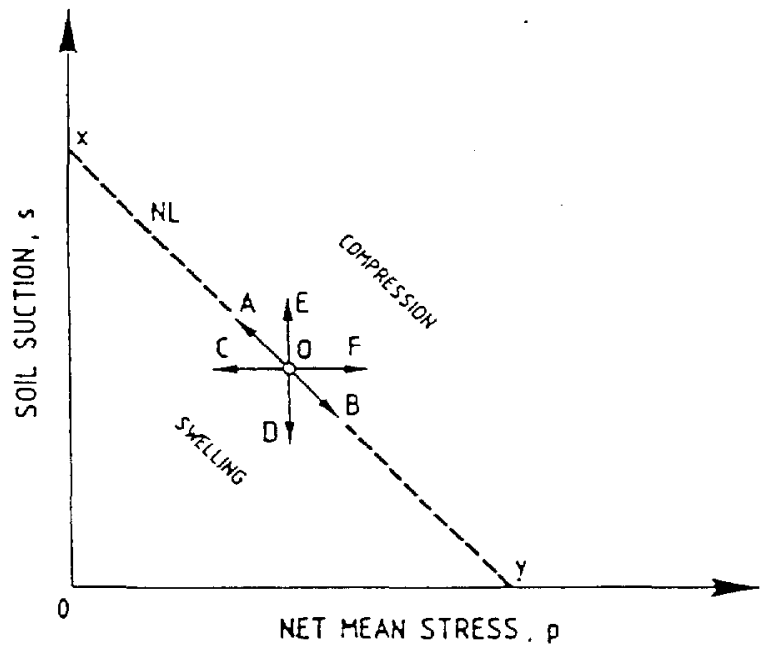

Fig. 1. Microstructural behaviour: neutral loading line.

participated in a CEC project on unsaturated clay behaviour. In the framework of this project, several laboratory experiments were carried out on Boom clay, FoCa clay and Almeria bentonite to validate the model about unsaturated expansive clays developed by Alonso and Gens, and to build a database of unsaturated clay parameters.

Boom clay was chosen in Belgium as a potential host rock for high radioactive waste disposal. The Boom clay is situated, under the nuclear site of Dessel-Mol, at a depth between 170 and $270 \mathrm{~m}$.
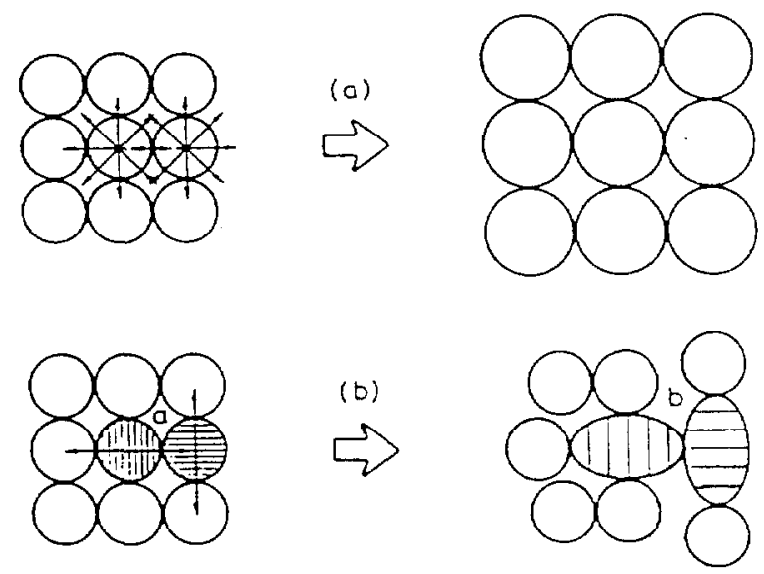

Fig. 2. Sketches to illustrate the effect of aggregate expansion on overall porosity. (a) Isotropic expansion of particles; (b) aggregate expansion along preferred orientations.
Boom clay exhibits favourable characteristics both as host rock and as engineered barrier, due to its low permeability, plasticity, and its high retention capacity for radionuclides.

The first part of the paper presents the interpretive model of Alonso and Gens. In the second part the laboratory experiments involving suction control (in particular oedometer experiments) carried out on Boom clay by SCK $\cdot$ CEN are described. The results are interpreted and related to the model. Comparison with the results obtained by CIEMAT and UPC is also discussed.

In this study, we have limited ourselves to a temperature below $100^{\circ} \mathrm{C}$, which is the maximum temperature for unsaturated backfill in many repositories' reference designs in granite and clay.

\section{Expansive soils}

Expansive soils are characterized by large swelling volumetric strains when wetted. Conversely, water content reductions (drying) leads to volume reduction (shrinkage). An examination of the relevant literature reveals a number of features which provide a distinctive character to soil expansion phenomena (Alonso et al., 1990, 1991):

- Expansive soils contain significant proportions of clay minerals, often highly swelling or active. However, all clays swell to some extent, and a key factor which controls the amount of swelling for all types of clay minerals is soil density.

- Swelling strains in a wetting path depend on: (a) initial water content (the lower the initial water content the larger the resulting final strain); (b) applied confining stress (confining stresses reduce the amount of induced swelling).

- Swelling pressure, as determined in wetting tests at zero volumetric deformation, is mainly controlled by the initial dry density (or void ratio) of the soil.

- Very marked stress-path dependencies are observed when testing expansive clays under loading-unloading and wetting-drying cycles. In addition, reversible and irreversible components of strains are identified along these paths. Traditionally, the behaviour of expansive clays 

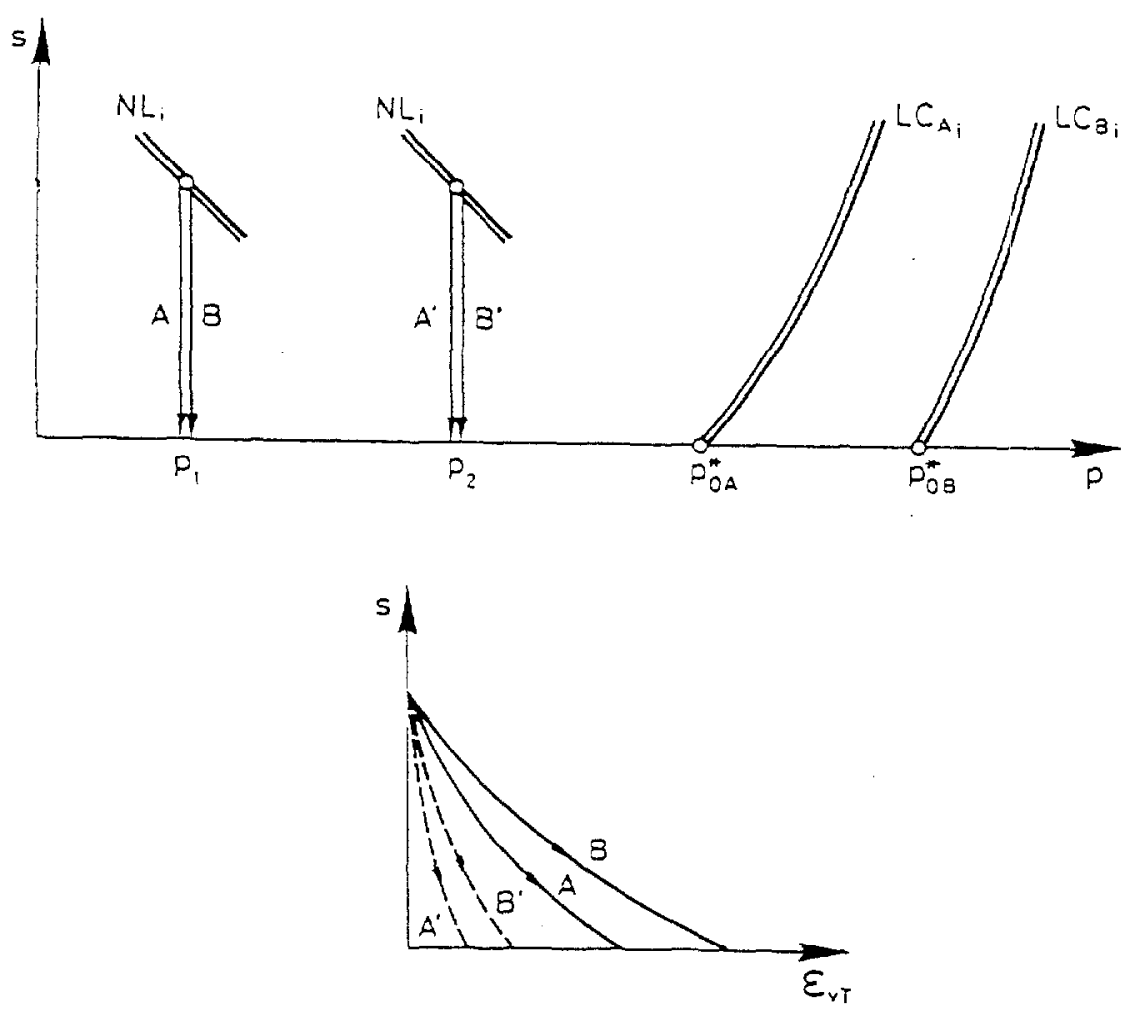

Fig. 3. Effect of the relative position of the LC yield curve on the magnitude of swelling.

is closely associated with physico-chemical phenomena at the particle level. These interactions take place, however, within a complex soil structure where other factors have a significant role. Probably the most important of these factors is the negative pressure of the water filling the interconnected voids of the soil (referred to hereafter as the macrostructure). In contrast, physicochemical effects affect mainly the water linked to the individual clay platelets or larger units of closely packed particles (referred to hereafter as the microstructure).

\section{Interpretive model of Alonso and Gens}

Theories for the expansion at microstructural level contemplate the interaction between a single particle and the surrounding ionized water. It will be assumed that a model exists to calculate volume change at particle level. The double layer theory may be used although other alternative empirical approaches (Low, 1980) may be adopted. Since the clay aggregates will likely remain saturated under the suctions prevailing in geotechnical environments, the principle of effective stress will be valid within the aggregates. Accordingly, changes in microstructural volumetric strains, $\epsilon_{\mathrm{vm}}$, will depend on effective mean stress, $(p+s)$, and possibly on other factors. In a $(p, s)$ space, stress paths for which $p+s=$ constant imply zero microstructural volumetric change (see Fig. 1). For this reason the straight lines $p+s=$ constant have been called Neutral Lines (N1). The microstructure will undergo compression or swelling whenever $p+s>0$ or $p+s<0$, respectively (Alonso et al., 1990, 1991).

Microstructural volumetric deformations will be assumed to be reversible in accordance with theoretical models of particle--water-ion systems and some experimental evidence (Warkentin et al., 1957). 

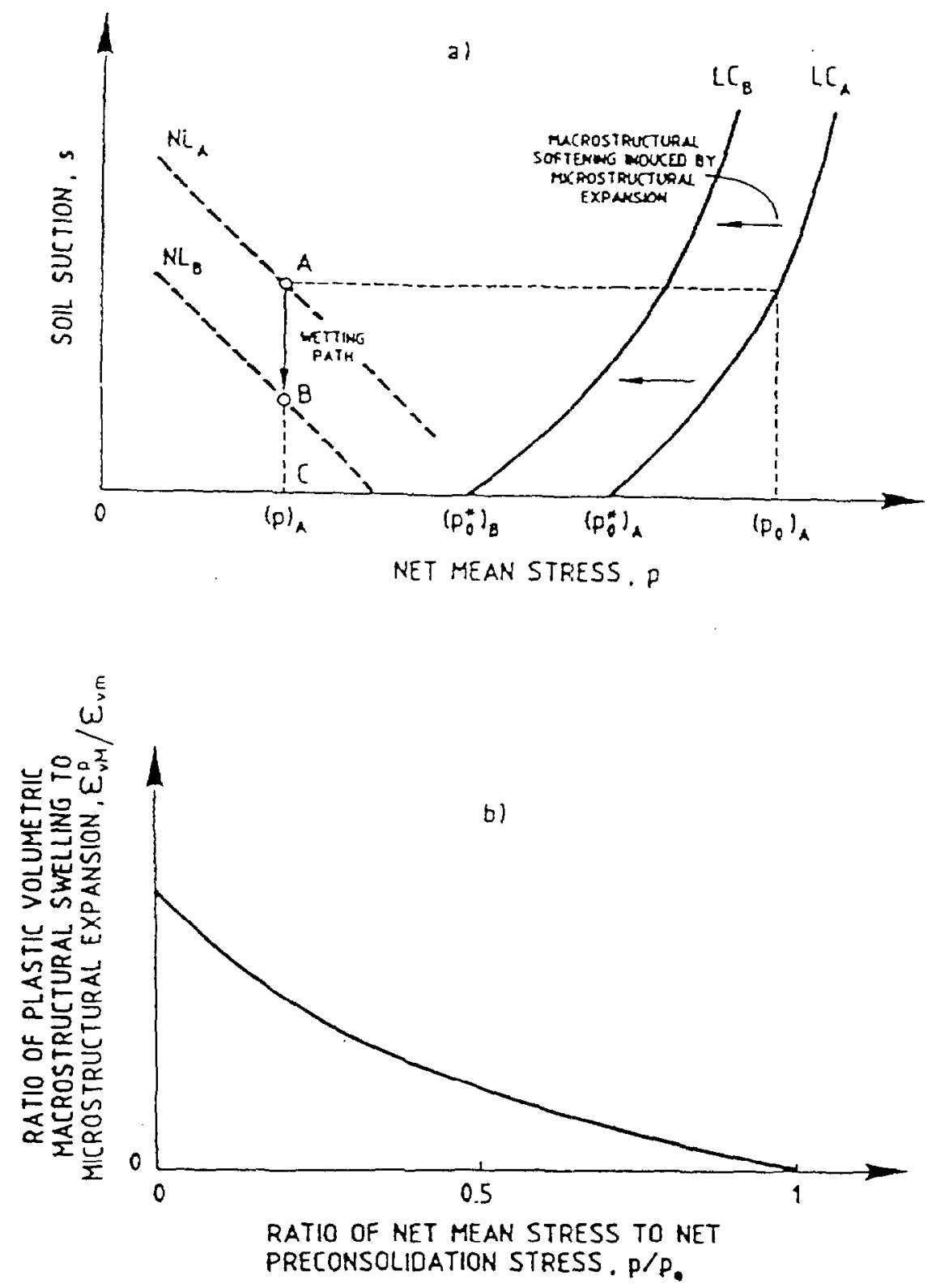

Fig. 4. Coupling between macrostructure and microstructure. (a) LC and NL yield loci; (b) variation of macrostructural plastic volumetric strain with applied net stress.

The second additional assumption refers to the interaction between the two structural levels defined. Microstructural behaviour is assumed to be independent of macrostructure but the reverse is not true. This statement is illustrated in the sketches in Fig. 2, which represent an idealized expansive granular medium whose spherical particles may swell. Under the idealized conditions of Fig. 2(a) an isotropic swelling of all the spheres will lead to an overall swell, but the macrostructural porosity will remain essentially unchanged. Microstructural swelling is, however, related to the 
Table I

Mineralogy and some important hydro-mechanical properties of the considered clays (NEA/SEDE, 1995)

\begin{tabular}{lc}
\hline & Boom clay \\
\hline Mineralogy (wt.\%) & \\
Clay minerals & 60 \\
illite & $20-30$ \\
smectite & $10-20$ \\
chlorite & $5-20$ \\
kaolinite & $20-30$ \\
mixed illite/smectite & $5-10$ \\
mixed chlorite/smectite & $5-10$ \\
Quartz & 20 \\
Feldspars & $5-10$ \\
Carbonates & $1-5$ \\
Pyrite & $1-5$ \\
Organic carbon & $1-5$ \\
Hydro-mechanical properties & \\
Total porosity (\%) & $36-40$ \\
Ilydraulic conductivity (m s & -1 ) \\
Young's modulus (elasticity) (MPa) & $2 \times 10^{-12}$ \\
Plasticity index IP (\%) & $200-400$ \\
\hline
\end{tabular}

change of interparticle distance within the aggregates and would show in clays a marked preferred orientation. The sketch in Fig. 2(b) indicates that swelling along preferred orientations is likely to produce an increase in macrostructural pore space (compare pores $a$ and $b$ in Fig. 2). In fact, swelling experiments in which suction reversals are induced (Chu and Mou, 1973; Pousada, 1984) indicate that a large proportion of the first swell is not recovered when suction is again increased. This irreversible macrostructural swelling strain will be named, $\epsilon_{\mathrm{vM}}^{p}$.

The final postulate of the framework refers to the relationship between $\epsilon_{\mathrm{vm}}$ and $\epsilon_{\mathrm{vM}}$. It was assumed that this relationship depends on the applied net mean stress and more specifically on the ratio $p / p_{0}$ in such a way that it becomes zero when $p=p_{0}$. The rationale behind this assumption is that $p=p_{\mathrm{o}}$ corresponds to an open macrostructure susceptible of collapsing. Decreasing values of $p / p_{\mathrm{o}}$ imply denser packings and therefore the ratio, $\epsilon_{\mathrm{vM}}^{p} / \epsilon_{\mathrm{vm}}$ should increase as $p / p_{\mathrm{o}}$ decreases.

The effect of this assumption is illustrated in Fig. 3. Samples A and B are at the same stress/suction point but they have different initial $\mathrm{LC}$ yield curves, $\mathrm{LC}_{\mathrm{Ai}}$ and $\mathrm{LC}_{\mathrm{Bi}}$. As shown in the lower part of Fig. 3, specimen B will swell more than specimen $\mathrm{A}$ upon saturation. Although the microstructural swelling will be the same in both samples, the irreversible macrostructural strains induced by the microstructural expansion will be higher for specimen $B$ because the distance from the stress point to its LC yield curve is larger than for specimen $\mathrm{A}$. Comparing the results of tests $\mathrm{A}$ and $\mathrm{A}^{\prime}$, the framework will predict that the swelling due to saturation will be far higher in the case of sample A. The origin of the difference is two-fold. Firstly the microstructural swelling is larger in sample A because of the lower applied stress but, in addition, the macrostructural strains induced by microstructural swelling will also be higher in sample A because of its higher distance to the corresponding LC yield curve. The same considerations apply to the comparison between specimens $\mathrm{B}$ and $\mathrm{B}^{\prime}$.

A relationship of this kind has been plotted in Fig. 4. Note in Fig. 4(a), which indicates the wetting path and the assumed initial positions of the neutral line $\left(\mathrm{NL}_{\mathrm{A}}\right)$, that the plastic swelling volumetric strain will induce a weakening of the structure (void ratio increases) and therefore the yield locus $\mathrm{LC}_{\mathrm{A}}$ will move to a position $\mathrm{LC}_{\mathrm{B}}$ during wetting. The neutral line may therefore be interpreted as a yield locus because, when it is reached in wetting paths, plastic strains are induced.

Irreversible macrostructural volumetric deformations may also occur along drying paths. Drying of aggregates reduces their volume, and the change in pore space is available for rearrangements of the soil structure. Experiments with drying-wetting cycles show plastic compression of the soil (Yong et al., 1971; Josa et al., 1987). As a consequence the neutral line may also behave as a yield locus in drying paths.

\section{Test programme}

A test programme was proposed by Gens and Alonso for the backfill material of the BACCHUS 2 experiment (mixture of Boom clay powder and high compacted Boom clay pellets; Volckaert et al., 1994 ) and the surrounding Boom clay in order to verify and calibrate their model. The test pro- 


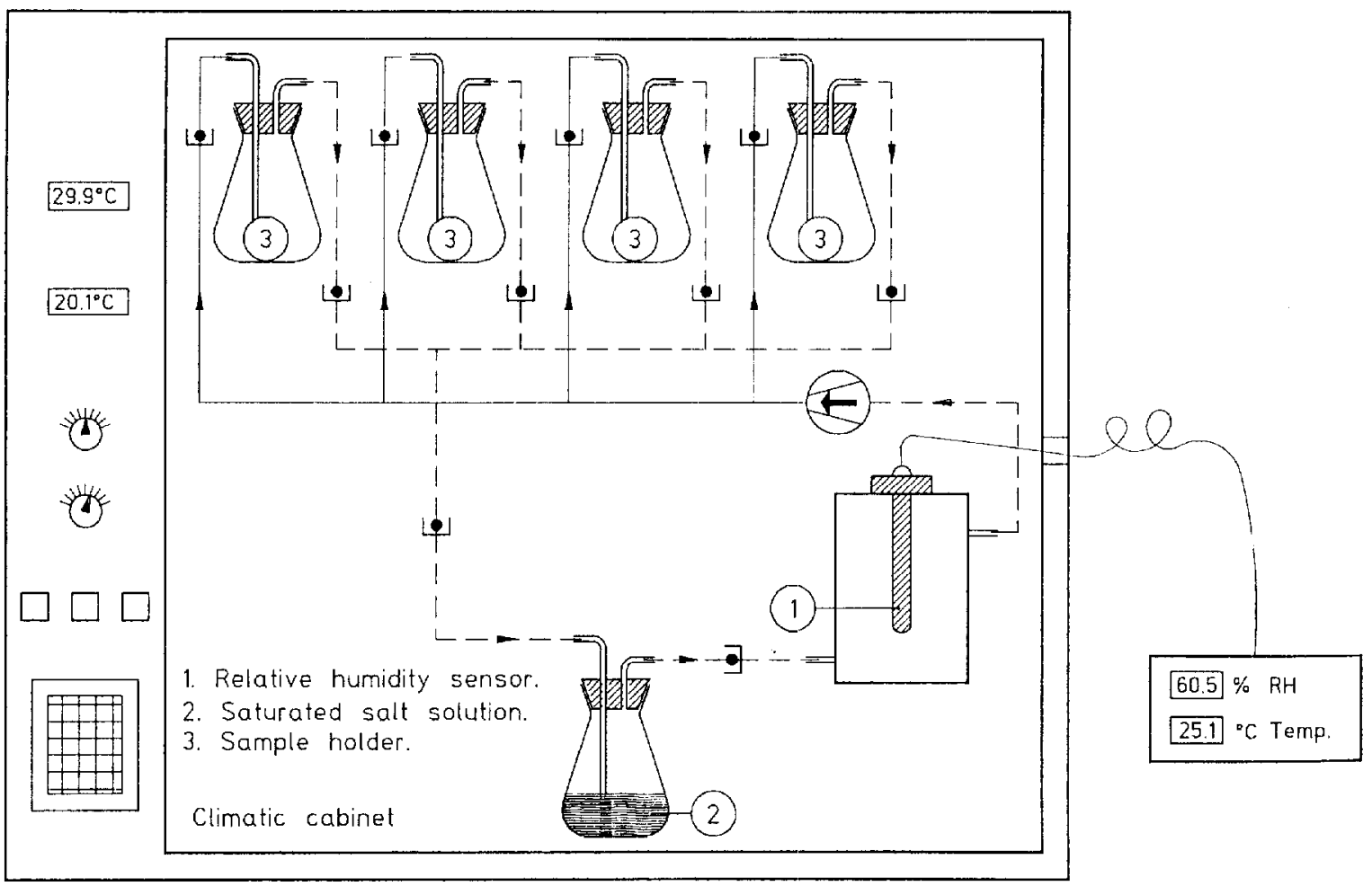

Fig. 5. Experimental set-up for the water content suction relation measurement.

gramme was designed to provide the necessary parameters for the mechanical model being used in the full-scale simulation. In addition, the suction-controlled tests are the most useful to validate the constitutive model. The proposed tests also provide data to derive the permeability of the materials tested for the range of suctions being applied. The results of these tests may also be interpreted and synthesized in terms of the state surface models.

SCK $\cdot$ CEN has carried out three types of tests involving suction control as a part of this test program:

- tests to establish the water content-suctiontemperature relation;

- suction-controlled oedometer tests at a constant vertical stress;

- suction-controlled oedometer test at constant volume.

Boom clay powder was used as test material.

\section{Main characteristics of Boom clay}

The Boom clay formation of north-east Belgium is a marine deposit of Rupelian (Middle Oligocene) age, i.e., 30-35 million years. The unit consists predominantly of intimately mixed clay and silt and minor sand. Bedding is mainly defined by rhythmic decimetre-scale variations in mean grain size (Van Echelpoel and Weedon, 1990). The carbonate-rich levels contain widely spaced septarian limestone nodules (Vandenberghe and Laga, 1986). Some beds also contain pyrite concretions and/or important fractions of organics. Although the Boom clay is of marine origin, its porewater is dominated by sodium bicarbonate. At Mol, the burial depth of the Boom clay layer is $180 \mathrm{~m}$ and its thickness is about $100 \mathrm{~m}$. From a hydrological viewpoint the Boom clay is an aquitard with very low hydraulic conductivity and, from a geomechanical viewpoint, it is an overconsolidated 


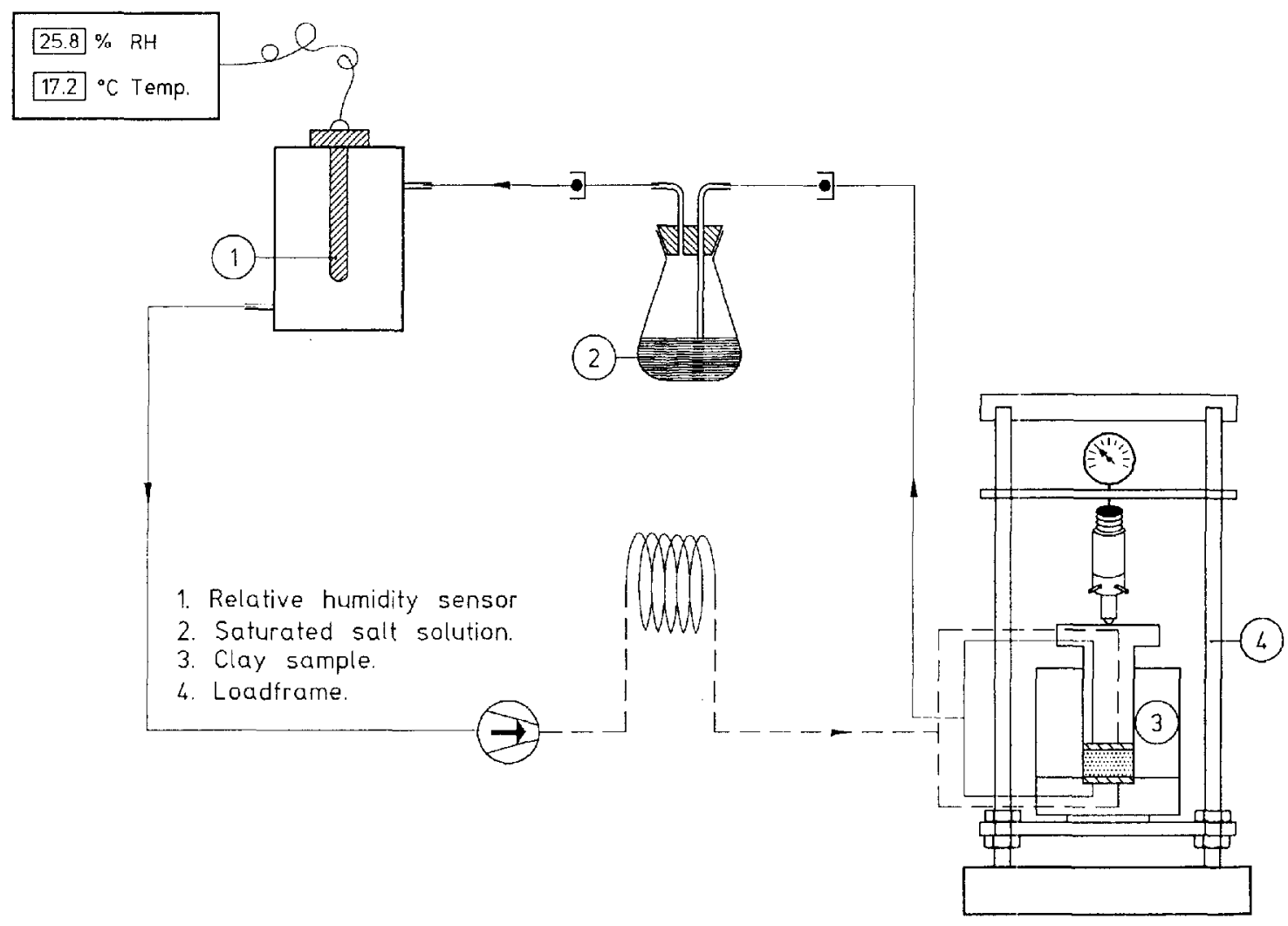

Fig. 6. Experimental set-up of the suction-controlled oedometer.

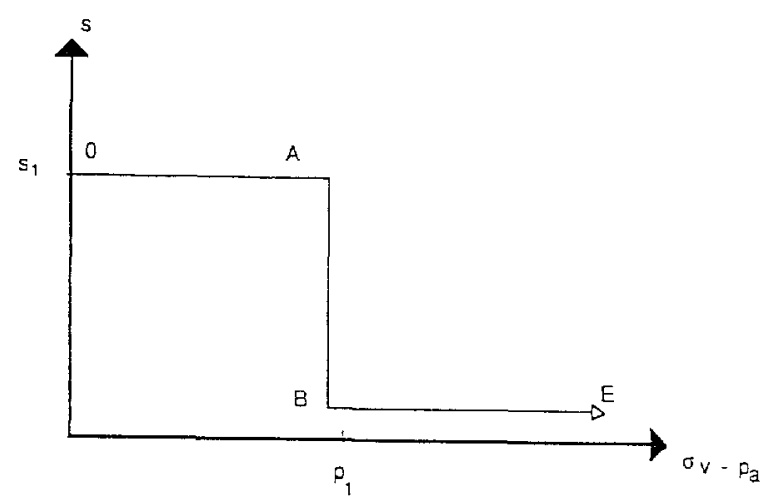

Fig. 7. Stress path OABE followed to detcrminc the swelling-suction relation.

plastic clay. The density of Boom clay at $223 \mathrm{~m}$ depth is about $1.7 \mathrm{~g} \mathrm{~cm}^{-3}$. The mineral composition and some important hydro-mechanical properties of the Boom clay are given in Table 1 .

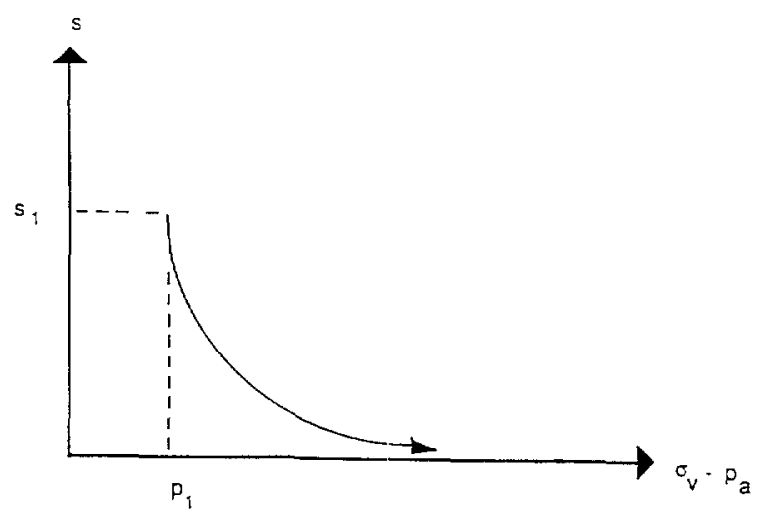

Fig. 8. Stress path followed to determine the swelling pressure-suction relation.

\section{Applied suction control principle}

It is well known that the vapour pressure of a liquid depends on the curvature of its surface. 
Water content - suction relation $\left(25^{\circ} \mathrm{C}\right)$

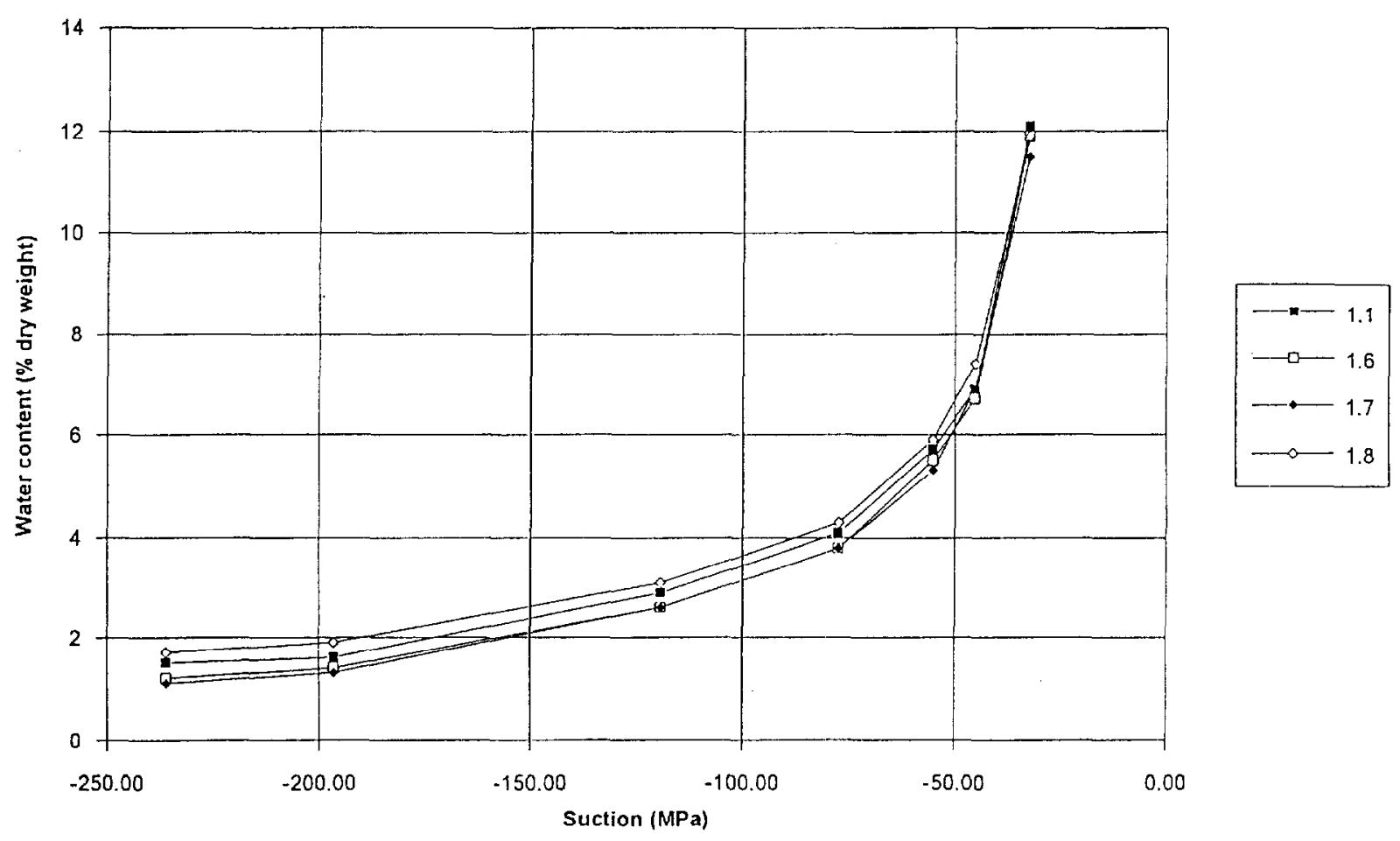

Fig. 9. The water content-suction relation for Boom clay at $25^{\circ} \mathrm{C}$ as a function of the density.

Therefore it is possible to control the suction in a backfill plug by imposing the relative humidity of the air injected in it. The dependence between the relative humidity and the suction can be expressed by the Kelvin equation:

$R T \ln h_{\mathrm{r}}=\frac{M_{\mathrm{w}}}{\rho_{\mathrm{w}}} S$

with $R$ the gas constant; $T$ the temperature; $h_{\mathrm{r}}$ the relative humidity; $M_{\mathrm{w}}$ the molecular mass of water; $\rho_{\mathrm{w}}$ the density of water; $S$ the suction.

The relative humidity can be imposed by the use of a climatic cabinet or different salt solutions. The two systems were tested. The climatic cabinet system appeared more flexible but less accurate than the salt solutions. Therefore only the salt solutions technique was used to carry out the tests and the climatic cabinet was used to ensure a constant homogeneous temperature in the experimental set-up.

CIEMAT and UPC have applied two other suction-control techniques: the control of the relative humidity by sulphuric acid solutions for high suctions, and the air pressure technique allowing to operate at lower suctions.

\section{Experimental set-up for the water content-suction relation determination}

The experimental set-up is shown in Fig. 5, and consists of an air circulation pump, a reservoir with the saturated salt solution, a relative humidity and temperature sensor, and four glass sample holders. All components are connected in a closed loop. The air passes first over the saturated salt 
Water content - suction relation $\left(1.7 \mathrm{~g} / \mathrm{cm}^{3}\right)$

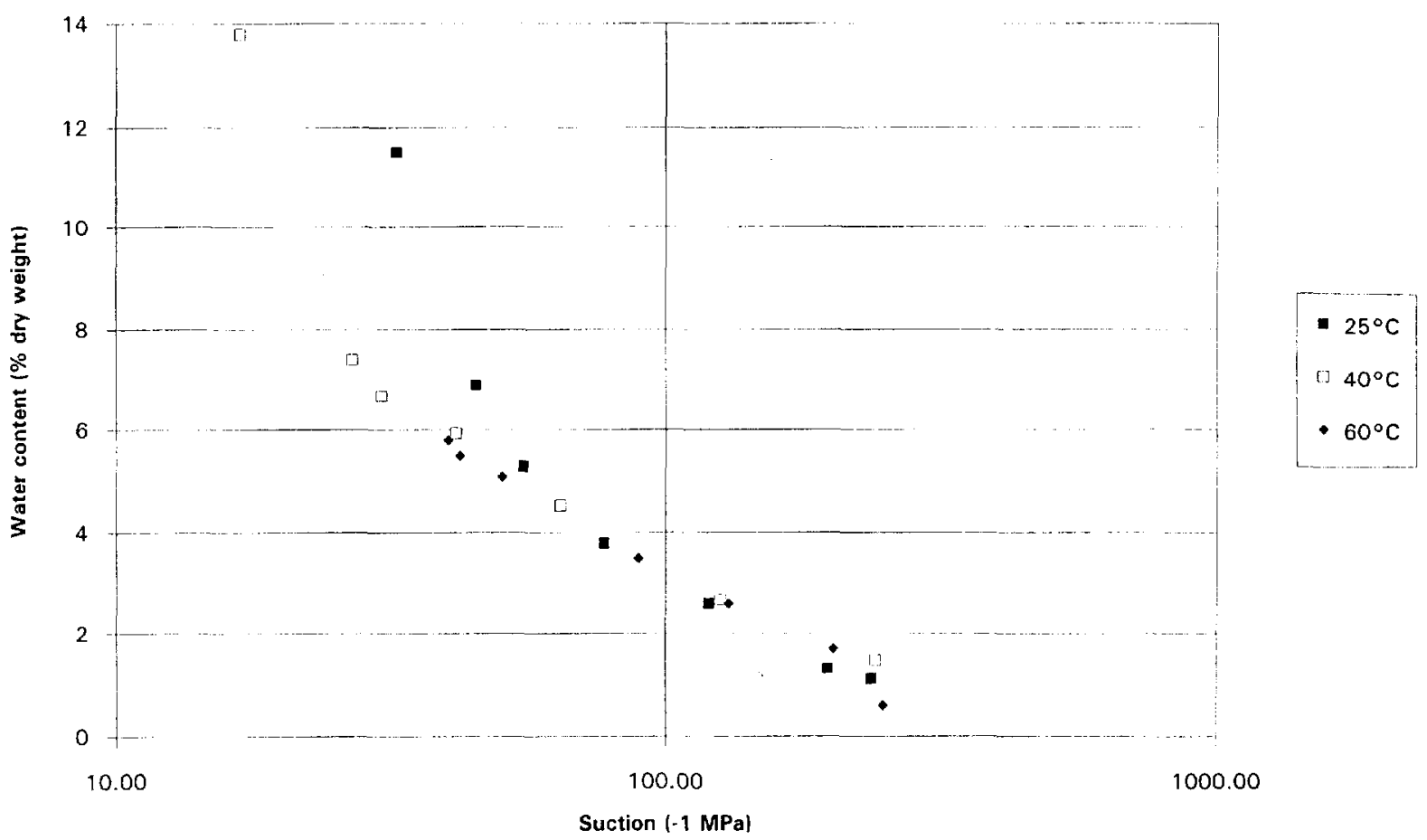

Fig. 10. The water content-suction relation for Boom clay with a density of $1.7 \mathrm{~g} \mathrm{~cm}^{-3}$ as a function of the temperature.

solution and gets a constant relative humidity. The air flow is split into four parallel flows through four sample holders. Finally, the four flows are recombined and pass through the circulation pump. The use of a circulation pump has the advantage of creating a high flow rate and, thus, a fast humidity exchange between the saturated salt solution and the clay samples. The sample holders are connected to the circuit by quick connectors, allowing the sample holders to be disconnected and weighted without disturbing the system. The water uptake of each sample is measured by weighing the whole sample holder. The total water uptake of the samples can be controlled by measuring the weight loss of the saturated salt solution. So, the sample is not taken out of the holder and its controlled humidity environment. The whole system is placed in a climatic cabinet to control the temperature. This assembly allows to measure the water content-suction relation on four samples at the same time and for a temperature between 25 and $70^{\circ} \mathrm{C}$.

\section{Experimental set-up for the oedometer test}

The experimental set up is shown in Fig. 6 and consists of an air circulation pump, a reservoir with the saturated salt solution, a relative humidity and temperature sensor, and an oedometer. All components are included in a closed loop. An existing oedometer was adapted to reduce as much as possible the suction equilibration time. Two rings were therefore inserted to facilitate the humidity exchange between the air and the clay plug.

The air passes first over the saturated salt solution and achieves a constant relative humidity before being injected into the oedometer. As can be seen in Fig. 6, the air flow passes in parallel 


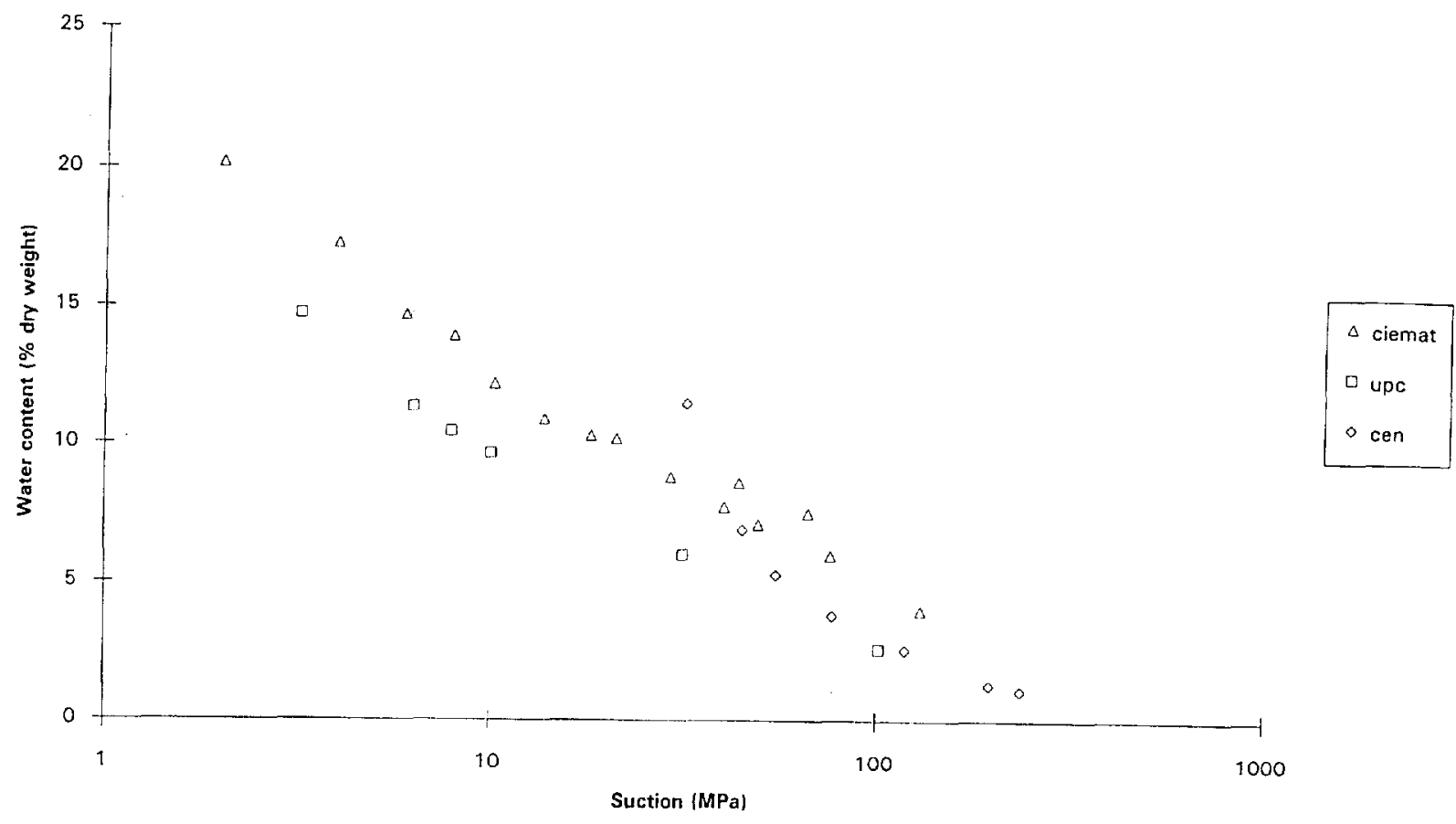

Fig. 11. The water content-suction relation for Boom clay compared with the results of CIEMAT and UPC for an initial dry density of $1.7 \mathrm{~g} \mathrm{~cm}^{-3}$ at room temperature.

over the top and bottom surface of the $1-\mathrm{cm}$ thick clay plug. This allows to limit the equilibration time to about 1 week.

Two types of oedometer tests were realized:

- with a constant vertical stress to detcrmine the suction-swelling relation (see stress path on Fig. 7);

- with a zero sample deformation to determine the suction-swelling pressure relation (see stress path on Fig. 8).

\section{The water content-suction relation for Boom clay}

The water content-suction relation for Boom clay has been measured at 25,40 and $60^{\circ} \mathrm{C}$ and for four different dry densities, i.e., the density of Boom clay powder $\left(1.1 \mathrm{~g} \mathrm{~cm}^{-3}\right)$, the dry density of natural Boom clay $\left(1.7 \mathrm{~g} \mathrm{~cm}^{-3}\right)$, and of a Boom clay-based backfill material such as used in the BACCHUS 2 experiment ( 1.6 and $1.8 \mathrm{~g} \mathrm{~cm}^{-3}$ ) (Volckaert et al., 1994). The higher density samples were made by uniaxial compaction of oven-dried Boom clay powder. The sample diameter is $19.6 \mathrm{~mm}$.

The water uptake for the different samples at the same suction is almost equal. Apparently the dry density has only a minor effect on water uptake (see Fig. 9). The most acceptable explanation is that the intra-aggregate porosity and smectite content is not affected by the compaction. Indeed, in the applied range of suction, the water uptake occurs in the intra-aggregate porosity, which is mainly governed by the electro-chemical forces exerted by the smectite in the clay samples.

Fig. 10 shows the influence of the temperature on the water uptake for a dry density of $1.7 \mathrm{~g} \mathrm{~cm}^{-3}$. We can see that, for the studied densities, the water uptake at 40 and $60^{\circ} \mathrm{C}$ is almost equal. Therefore the increase in temperature seems to have only a slight influence on the electrochemical forces (decrease of the attraction forces). The water uptake is a bit higher for a suction greater than $-100 \mathrm{MPa}$ at room temperature than at higher temperature. However, this observation 
Suction - swelling $=1.7 \mathrm{~g} / \mathrm{cm} 3 /$ vert. str. $=1 \mathrm{MPa}$

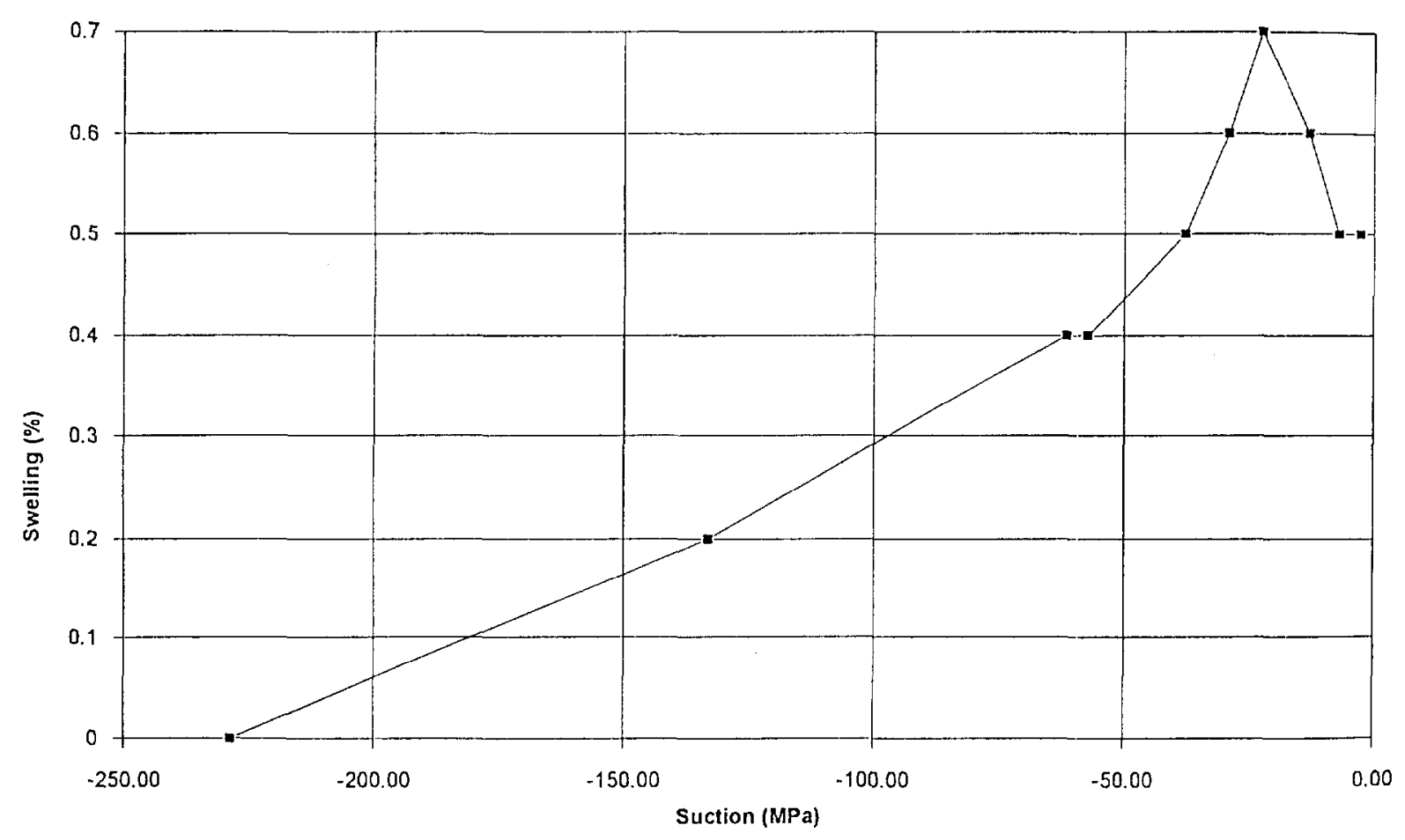

Fig. 12. Suction-swelling relation for Boom clay (density $=1.7 \mathrm{~g} \mathrm{~cm}^{-3}$ and applied vertical stress $=1 \mathrm{MPa}$.

has to be interpreted carefully since by comparing the results of CIEMAT and UPC in Fig. 11, this point is outlying. This behaviour was, however, already observed by experiments performed by CIEMAT (Villar et al., 1993). A laboratory experiment, in which a compacted bentonite block (montmorillonite Almeria clay) was submitted to simultaneous heating and hydration, has been designed with the aim of simulating the heat/water flow interaction in the barrier. They have observed that, without hydration, the final water content decreases near the heater and increases in points further away.

The water content-suction relationship for Boom clay was compared with the results of CIEMAT and UPC carried out with the same clay for an initial dry density of $1.7 \mathrm{~g} \mathrm{~cm}^{-3}$ at $25^{\circ} \mathrm{C}$. We can see from Fig. 11 that the results are close even if different oedometer designs and different suction-control techniques were used by the three Institutes.

\section{The swelling-suction relation for Boom clay}

The suction-swelling relation has been measured by performing suction-controlled oedometer tests under constant vertical stress. The stress path is given in Fig. 7. The tests have been performed on a 1-cm thick clay plug with a density of $1.7 \mathrm{~g} \mathrm{~cm}^{-3}$, and for five vertical stresses $(0.1,0.5$, 1,2 and $4 \mathrm{MPa}$ ). For the test with a constant vertical stress of $0.5 \mathrm{MPa}$, a complete wetting/ drying cycle was performed.

With the decrease of suction we observed a swelling for the test at $0.1 \mathrm{MPa}$, and a swelling followed by a collapse for the tests at 1 (see Fig. 12) and $2 \mathrm{MPa}$. As shown in Fig. 13 this 

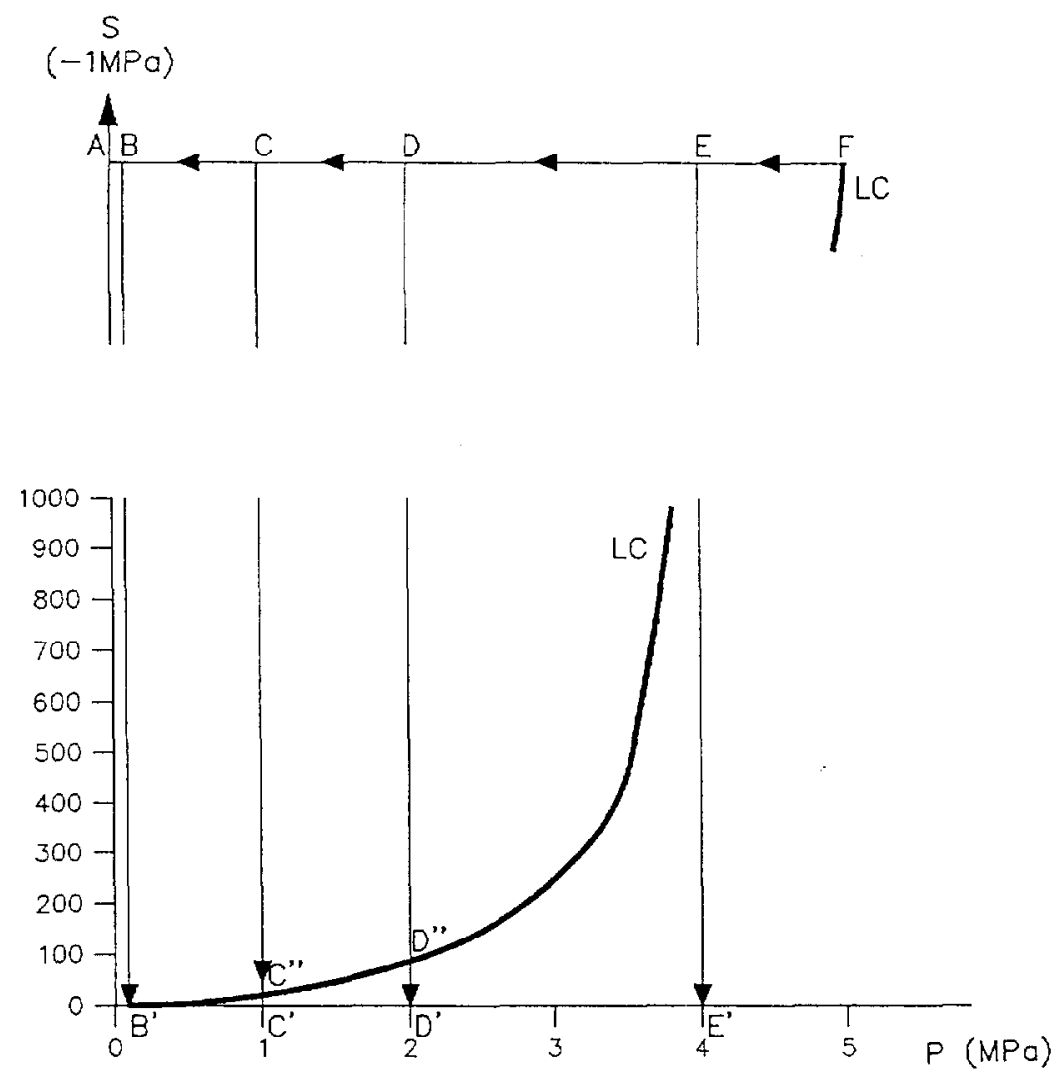

Fig. 13. Theoretical interpretation for the oedometer test.

bchaviour is in agreement with the model developed by Alonso and Gens. To obtain a density of $1.7 \mathrm{~g} \mathrm{~cm}^{-3}$ the sample is compacted at a pressure of $5 \mathrm{MPa}(\mathrm{A}-\mathrm{F})$. The sample is then loaded at $0.1,1,2$ and $4 \mathrm{MPa}$ following, respectively, the pathways $\mathrm{F}-\mathrm{B}, \mathrm{F}-\mathrm{C}, \mathrm{F}-\mathrm{D}$ and $\mathrm{F}-\mathrm{E}$. The suction decreases (up to 0) following $\mathrm{B}-\mathrm{B}^{\prime}, \mathrm{C}-\mathrm{C}^{\prime}, \mathrm{D}-\mathrm{D}^{\prime}$, E $E^{\prime}$. Path B B' does not cross the L-C (load-collapse) curve and thus only leads to swelling. Paths $\mathrm{C}-\mathrm{C}^{\prime}$ and $\mathrm{D}-\mathrm{D}^{\prime}$ cross the $\mathrm{L}-\mathrm{C}$ curve respectively on $\mathrm{C}^{\prime \prime}$ and $\mathrm{D}^{\prime \prime}$, and present a swelling followed by a collapse. In the case of a loading of $4 \mathrm{MPa}$ (F-E-E'), the sample collapse without previous swelling.

Fig. 14 shows the effect of the applied vertical stress on the swelling/collapse behaviour of wetting compacted Boom clay (suction $=0$ ). The results are compared with the results obtained by UPC. The differences of the results are in the range of experimental precision. We can therefore consider that the results are in good agreement.

\section{The swelling pressure-suction relation for Boom clay}

Swelling pressure tests were also performed with oedometers under suction control. Boom clay samples were compacted to a dry density of $1.7 \mathrm{~g} \mathrm{~cm}^{-3}$. Sample deformation was maintained to zero at all stages during the wetting, and the vertical pressure was measured. This test was carried out with two different initial vertical pressures: 0.15 and $0.4 \mathrm{MPa}$. At each wetting stage, the swelling pressure increases, reaches a maximum value and then decreases to an equilibrium, due to the relaxation effect. The maximum values are reported as a function of the suction in Fig. 15. 


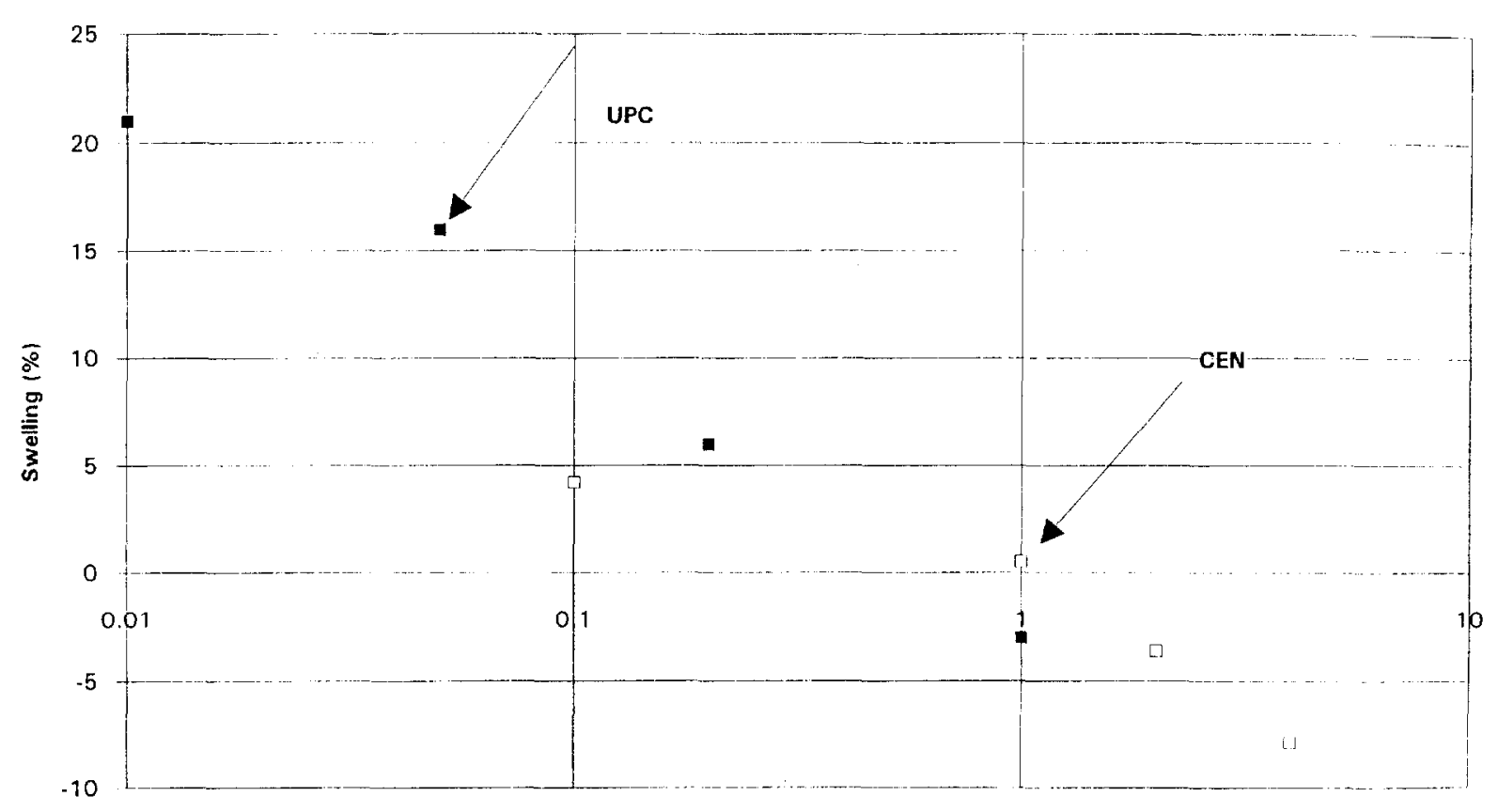

Vertical pressure (MPa)

Fig. 14. Effect of applied vertical stress on swelling/collapse upon wetting of Boom clay $\left(1.7 \mathrm{~g} \mathrm{~cm}^{-3}\right)$ : comparison of the results of UPC and SCK $\cdot$ CEN.

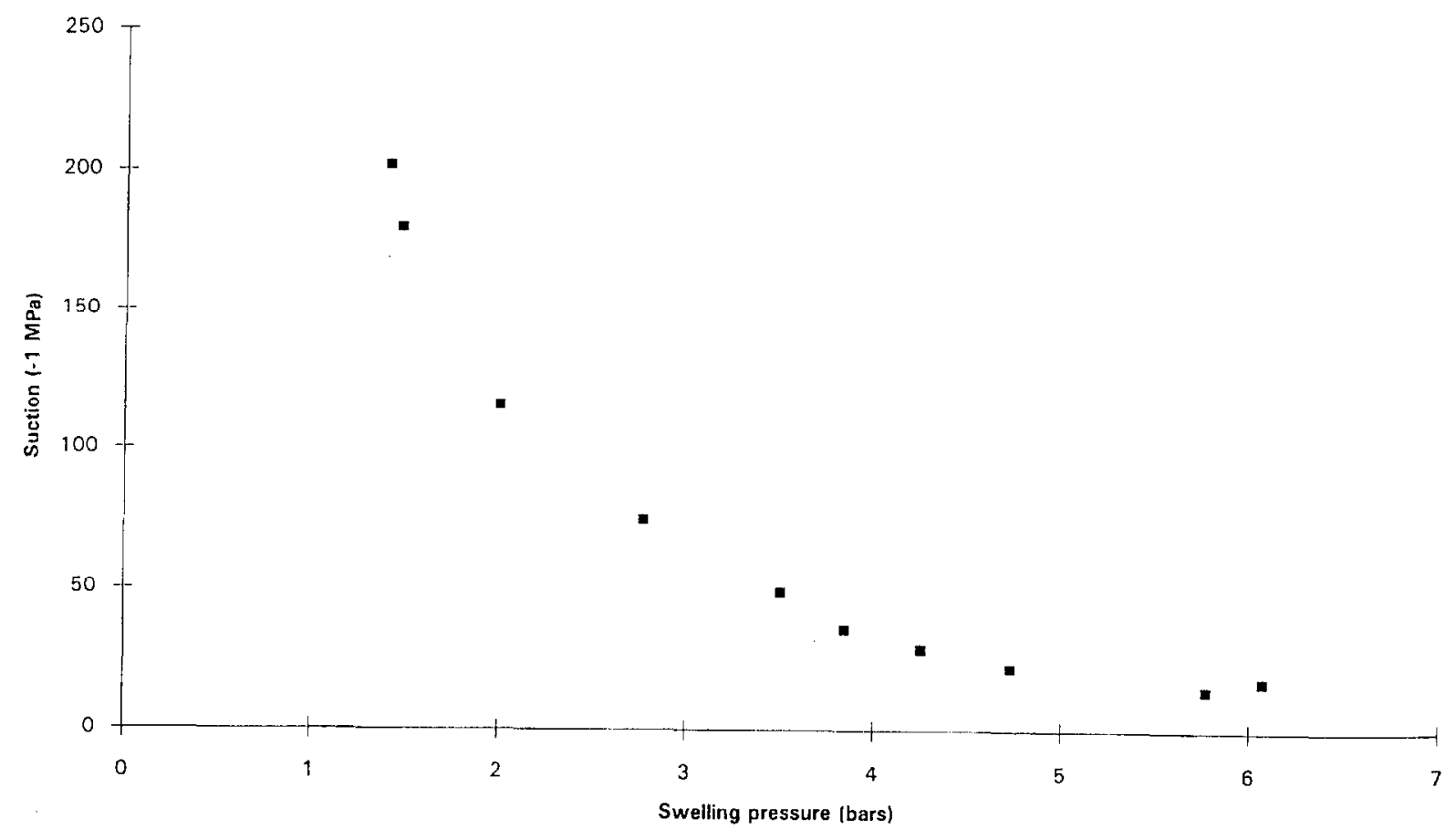

Fig. 15. Suction-swelling relation for Boom clay (density, $1.7 \mathrm{~g} \mathrm{~cm}^{-3}$ : initial vertical stress, $0.15 \mathrm{MPa}$ ). 
The relation between swelling and suction is logarithmic. For a relative humidity greater that $90 \%$, the difference between the swelling pressures for the two tests is only $0.05 \mathrm{MPa}$ while at the beginning the difference in stress was $0.25 \mathrm{MPa}$. The swelling pressure near the saturation seems to remain in the same range $(0.6-0.7 \mathrm{MPa})$ for all initial vertical stresses.

\section{Conclusion}

The conducted experiments allowed to extend the Boom-clay database with thermal, suction and hydro-mechanical data.

We have shown that the obtained results about the water content suction relationship for Boom clay are in agreement with the results of CIEMAT and UPC for an initial dry density of $1.7 \mathrm{~g} \mathrm{~cm}^{-3}$ at $25^{\circ} \mathrm{C}$. Thus equivalent results are obtained with different oedometer designs and different suctioncontrol techniques used by three different institutes.

The results of the suction-controlled hydromechanical tests validate the Alonso and Gens model concerning the swelling-collapse behaviour of clay.

\section{References}

Alonso, E., Gens, A. and Josa, A., 1990. A constitutive model for partially saturated soils. Geotechnique, 40: 405-430.

Alonso, E., Gens, A. and Loret, A., 1991. Double structure model for the prediction of long-term movements in expansive materials. Conference on Computer Methods and Advances in Geomechanics, 541-548.

Chu, T.Y. and Mou, C.H., 1973. Volume change characteristics of expansive soils determined by controlled suction test. Proc. 3rd International Conference on Expansive Soils, Haifa, Vol. 1: 177-185.

Josa, A., Alonso, E.E., Lloret, A. and Gens, A., 1987. Stressstrain behaviour of partially saturated soils. Proc. 9th European Conf. Soil Mech. Fdn. Engng., Dublin, 2: 561-564.

Low, P.F., 1980. The swelling of clay. II. Montmorillonites. Soil Sci. Soc. Am. J., 44: 667--676.

Pousada, E., 1984. Deformabilidad de arcillas expansivas bajo succin controlada. Doctoral thesis, Universidad Politécnica de Madrid, Spain.

Villar, M.V., Cuevas, J., Fernandez, A.M. and Martin-Martin, P.L., 1993. Effects of the interaction of heat and water compacted bentonite. Preliminary results. CIEMAT and UAM. International Workshop on Thermomechanies of Clays and Clay Barriers, Bergamo.

Volckaert, G., Bernier, F., Alonso, E., Gens, A., Samper, J., Villar, M., Martin-Martin, P.L., Cuevas, J., Campos, R., Thomas, H., Imbert, C., Zingarelli, V., 1996. Thermalhydraulic-mechanical and geochemical behaviour of the clay barrier in radioactive waste repositories (model development and validation), Final Report, EUR 16744.

Vandenberghe, N. and Laga, P.. 1986. The septaria of the Boom Clay (Rupelian) in its type area in Belgium. Aardkundige Mededelingen, Vol. 3.

Van Echelpoel, E. and Weedon, G.P.. 1990. Milankovitch cyclicity and the Boom Clay Formation: an Oligocene siliciclastic shelf sequence in Belgium. Geol. Mag. 127(6).

Volckaert, G., Bernier, F., Alonso, E., Gens, A., Dardaine, M., 1994. BACCHUS 2: An In Situ Backfill Hydration Experiment for Model Validation. GEOVAL, Paris.

Warkentin, B.P., Bolt, G.M. and Miller, R.D., 1957. Swelling pressure of montmorillonite. Soil Sci. Soc. Am. Proc., 21: $495-497$.

Yong, R.N., Japp, R.D. and How, G., 1971. Shear strength of partially saturated clays. Proc. 4th Asian Reg. Conf. Soil Mech. Fdn Engng, Bangkok, 2, 12: 183-187. 